SCIREA Journal of Clinical Medicine

ISSN: 2706-8870

http://www.scirea.org/journal/CM

January 24, 2021

SCIREA

Volume 6, Issue 1, February 2021

\title{
Maillard reaction. Pathogenic effects.
}

\section{Luis E.Voyer ${ }^{1}$, Caupolicán Alvarado ${ }^{2}$}

${ }^{1}$ Teaching and Research. Pedro de Elizalde Hospital. Associated with Medicine School. Buenos Aires' University. Argentina

${ }^{2}$ Nephrology Department. Pedro de Elizalde Hospital. Associated with Medicine School. Buenos Aires' University. Argentina

\begin{abstract}
Maillard reaction. Pathogenic effects. Certain organoleptic modifications by way of processing and cooking foods at high temperatures in dry heat, make them especially appetizing and object of addiction. It results from Mayllard reaction, or glycation, consisting on the non-enzymatic union between carbonyl groups, mainly from reducing sugars as glucose and fructose, with the amino groups of proteins and nucleic acids. In addition of physical changes, also the chemical structure and function of these compounds are changed. Besides exogenous glycation generated during the cooking of foods, recently in situ glycation has been reported in the intestinal lumen during digestion, when certain non-glycated foods are combined with fructose at the time of ingestion. In addition, endogenous glycation, which correlates in the extracellular mainly with blood glucose and in the intracellular with glycolysis metabolites and fructose, is especially significant. Since the 70s, with the frequent sucrose replacement by fructose, much more reactive than glucose, the presence of glycation products in processed foods and soft drinks increased. Pathogenic effects of these compounds, also called glycotoxins, are known to contribute to oxidative stress and inflammation. This
\end{abstract}


increases progression of chronic diseases, well documented in diabetes, renal insufficiency, cardiovascular disease and ageing process and are being explored in many other chronic diseases as neurodegenerative diseases and early ageing. Based on the knowledge achieved so far, measures to preserve health are described by attending ways of cooking and processing foods, besides recomendations for the habits and antioxidants dietary intakes for inhibition or antagonism on glycotoxins.

Keywords: Mayllard reaction, glycation, glycotoxins, oxidative stress.

\section{Introduction:}

Maillard reaction ${ }^{1}$, or glycation, consists of the non-enzymatic union between carbonyl groups, mainly aldehydes or ketones from reducing sugars as glucose and fructose, with amino group of proteins and nucleic acids. Carbonyl groups are also generated during oxidative degradation of lipids. Glycation is related to concentration and contact time of involved substances, and the reaction is strongly accelerated in conditions of high temperature and low humidity (dry heat). Different foods show accelerated generation of these by-products at temperatures above $100-120^{\circ} \mathrm{C}$, and especially at $140^{\circ} \mathrm{C}$. The reaction is observed in grill, oven, griddle or fry cooking, and is facilitated by alkaline $\mathrm{pH}$, copperware and ironware. Cooking in copper or iron pots and adding sodium bicarbonate (as is usual in the elaboration of dulce de leche, a caramel made of sweetened milk), gets a darker final color through glycation.

Glycation is a well-known phenomenon in gastronomy, being responsible of toasted color with different shades of brown, due to pigments called melanoidins. Glycation, as well as lipid products derived from oxidation ${ }^{2}$, have influence in the appetizing changes in flavour and aroma that take place during the cooking of food products so different as roasted beef, croissants and french fries.

Glycation generates three types of

products: unstable and reversible compounds (Schiff bases), stable and potentially reversible compounds (Amadori products), and irreversible compounds (AGEs: Advanced Glycation End-products). 
Since 1976 it has been observed that a fraction of total hemoglobin is in the form of glycated hemoglobin (this denomination is preferred over "glycosylated hemoglobin" to reflect the correct non-enzymatic process). Increased levels of glycated hemoglobin (HbAlc) in diabetes correlates with elevated glucose levels, and is used by clinicians to monitor diabetes treatment ${ }^{3}$. Glycated compounds originated in lipid catabolism are known as ALEs (Advanced Lipooxidation End-products) ${ }^{4}$.

Glycation products can be measured in blood, urine and tissues by various methods, such as enzyme immunoassay, mono and polyclonal antibodies, autofluorescence, chromatography, or mass spectrometry, which is the most sensitive one. Carboxymethyl lysine, glyoxal and methylglyoxal are the best studied AGEs ${ }^{5}$.

Alcohol overconsumption, especially stout beer and sugar-rich liquors, is, through acetaldehyde production, an important contributor in AGEs generation ${ }^{6}$. Glycation products are retained in several organs and tissues or are partially metabolized into second-generation products that are excreted in urine $\mathrm{e}^{7,8}$.

Glycation research has interest in clinical medicine, especially in relation to diabetes. Glycated products are metabolized and excreted, but also deposited in different tissues and organs.

\section{Exogenous Glycation. Role of Fructose}

Exogenous glycation generates dietary AGEs (dAGEs). It has always been considered that this process took place almost exclusively during food cooking. Recently, it has been observed that a non-glycated food such as ovalbumin, ingested with apple juice, produces a rise of glycated compounds in serum and urine. It is considered in-situ glycation within the intestinal lumen, followed by systemic absorption of adducts. AGEs are generated in in vitro models of gastrointestinal digestion of ovalbumin in the presence of fructose (a carbohydrate more reactive than glucose). Chlorogenic acid, a main phenolic compound of yerba mate (Ilex paraguariensis), can inhibit the reaction, almost as potently as aminoguanidine, a wellknown inhibitor of glycation ${ }^{9-12}$.

Exogenous glycation, normally generated in foods during cooking, can also be produced in the intestinal lumen, due to fructose action over protein sources. 


\section{Endogenous Glycation}

Under physiological conditions, endogenous glycation is produced in small quantities during metabolic processes, both outside and inside cells. Extracellular glycation is the result of interaction between blood glucose and plasmatic proteins, and, consequently, increases with hyperglycemia. Fructose plays a minor role, since its serum concentration is less than $1 \%$ that of glucose, but has an important place in intracellular glycation. In the intracellular, glycolysis metabolites from glucose 6-phosphate and dicarboxylic precursors, glyoxal and methylglyoxal, have reactive activity for glycation ${ }^{13}$.

The special significance of fructose is that, besides being significantly more reactive than glucose, its intracellular concentration increases not only after ingestion, but with hyperglycemia, since glucose activates aldose reductase, that generates fructose from glucose $\mathrm{e}^{13}$.

Endogenous glycation occurring out of cells is related to glucose levels, while within cells the process has relation with glycolysis metabolites and fructose levels.

\section{Pathogenic Effects}

Glycation end-products, known also as "glycotoxins", are potentially harmful to health. They are highly reactive molecules that behave as electron donors during free radicals generation. The process contributes to oxidative stress, a main factor of cellular damage, that also enhances endogenous glycation.

AGEs activate specific receptors: RAGEs (Receptor Advanced Glycation End-products) ${ }^{14}$, proinflammatory cytokines (interleukin 1, interleukin 6), tumor necrosis factor- $\alpha$, insulin-like growth factor-1 and $\mathrm{C}$ reactive protein (CRP), that alter cell membranes permeability and vitality. Interaction AGEs-RAGEs mediates most biologic effects, including free radical generation, thus closing a vicious circle.

Free radicals also stimulate platelet activation and promote thrombosis. They contribute to vasoconstriction through reduced nitric oxide synthesis in smooth muscle of vessels wall, and through inhibition of plasminogen, an essential fibrinolytic compound.

Proinflammatory actions, thrombosis promotion and atherosclerosis are responsible of tissue damage, notably in liver, kidney, brain, lens and connective tissue, especially skin, cartilage and tendons ${ }^{4}$. 
AGEs, plasma and tissue proteins, in cross linked forms, interact with RAGEs located on endothelial surfaces especially of collagen, which may lead to microvascular or macrovascular disease, articular loss of flexibility and loss of mobility in joints.

Altered structural proteins in connective tissue interfere with osteoblastic differentiation and bone remodelling, and lead to skeletal fragility ${ }^{15}$.

Mediated by a chain of reactions, alterations are produced in protein chemical structure, and amino acids lose their normal three-dimensional configuration, leading to functional derangements with potential pathogenic effects. Nucleic acids may also suffer transformation in adducts, depurination and consequent deletion or mutation ${ }^{16}$.

It has also been observed reduced enzymatic activity in calcium pump, calmodulin and superoxide dismutase, and increased activity in aldose reductase. Changes in superoxide dismutase increase noxious effects of free radicals, alter cell membrane permeability, and modify (along with abnormalities in calmodulin and calcium pump) intracellular calcium concentration, a process that influences muscle contraction, genic expression, cell differentiation and neuronal functions ${ }^{17}$. Enhanced aldose reductase activity increases fructose concentration.

The greater or lesser protein involvement is related to protein half-life. Schiff bases and, to a lesser extent, Amadori products - mostly unstable and reversible products - may be observed in high turnover, short half-life proteins, implicated in cell renewal, like plasmatic proteins, red cell proteins, and proteins in organ such as intestine, skin and liver.

AGEs are observed in months or years of contact with long half-life proteins, such as those in lens, collagen or myelin sheaths, and also with nucleic acids. AGEs accrual in human tissues suffering micro and macrovascular damage — initially described in relation to diabetes - has actually been identified in advanced stages of renal disease, neurodegenerative diseases, chronic pulmonary obstraction, brain impairment, cardiovascular disease, cataracts, atherosclerosis and premature ageing, especially in skin and vascular endothelium ${ }^{18-21}$. Ageing can be viewed as a deleterious circle made up of oxidative stress, free radicals, mitochondrial damage and increasing intracellular calcium, boosted by glycation.

AGEs slowly affect tissue renewal, and long half-life proteins in dermis are especially prone to damage due to ultraviolet radiation-enhanced glycation.

Elderly persons with Type II diabetes and compromised cognition show AGE, RAGE and CRP high levels, correlated with $\mathrm{HbAlc}$ values $^{22}$. In senile plaques and neurofibrillary 
bundles and beta-amyloid plaques found in Alzheimer disease, AGE deposition is three times that of controls ${ }^{23}$.

So far less investigated, AGE deposits seemingly play a pathogenic role in other neurodegenerative diseases, such as Parkinson disease ${ }^{24}$, Lewy bodies dementia ${ }^{25}$, amyotrophic lateral sclerosis ${ }^{26}$, Huntington disease ${ }^{27}$ and Creutzfeldt-Jakob disease ${ }^{28}$. Elevated serum levels of AGEs and RAGE activation have been described in polycystic ovary syndrome ${ }^{29}$.

Diabetic patients are especially susceptible to glycotoxins, due to higher endogenous production; diabetic treatment, blood glucose control and dAGE reduction are relevant in prevention of chronic complications, like kidney disease, retinopathy and neuropathy.

Insulin-dependent diabetic patients with kidney involvement and retinopathy may present with articular stiffness in hands. This evident and simple semiological sign is important for diagnosis and can be further confirmed by palmar impression, lacking limiting marks between phalanges ${ }^{30,31}$.

In diabetic nephropathy, after an initial stage with functional alterations, a second stage ensues, characterized by thickening of basal membrane, mesangial expansion and changes in glomerular arteries. These lesions can not be attributed to immunological mechanisms, and alteration in structural proteins seems to be the main pathogenic factor.

Pregnant women with poor controlled gestational diabetes can give birth to newborns with congenital malformations, such as caudal regression sequence, from simple form (sacral agenesis), to most severe (sirenomelia or Mermaid syndrome). It is not known if these malformations represent a defect of caudal blastema, a defect in posterior mesoderm, an alteration of structural proteins in connective tissue or nucleic acids alterations ${ }^{32}$.

dAGE reduction is relevant not only in diabetes, but also in renal failure. Low dAGE diets in patients on continuous peritoneal dialysis for advanced renal failure correlates with better values of urea, creatinine, total proteins, albumin and phosphorus ${ }^{33}$.

Patients with chronic renal failure may suffer especially with reduced elimination of noxious carbonyl-group compounds, highly reactive for glycation (carbonyl stress). AGEs are pathogenic compounds responsible for induction and progression of kidney damage and cardiovascular complications. AGE-linked fluorescence can be detected in skin, and can be used as a prognosis marker of vascular damage and kidney failure in patients on hemodialysis or renal transplantation ${ }^{34}$. 
Within cells, AGE-associated damage is found especially in mitochondria, derangement of mitochondrial metabolism decreases energy production and conseqwently cytoplasmic glycolysis increases. Without access to Krebs cycle and respiratory chain, production of lactic acid as end-product, conforms the basis for cancer metabolic theory ${ }^{35,36}$. AGEs induce apoptosis, normally a mechanism for replacing aged or damaged ce3-1ls, for cell renewal during maturation and growth, and for defense in the face of a viral attack.

Research studies modifying diet to provide low or high dAGE, have not consistently shown correlation with serum or urine AGE levels, nor significant changes in inflammation markers, peripheral arteries tonometry or endothelial function ${ }^{37}$. These discordant observations have prevented definitive conclusions. Some experts have speculated that dAGEs are only partially absorbed, and those of with low molecular weight AGEs, do not interact with RAGE, though it has been proposed that could induce endogenous formation of high molecular weight AGEs.

AGE generation can also take place in situ in intestinal lumen, by means of fructose, high fructose corn syrup (HFCS), fruits or fruit juices, ingested along with protein-rich foods.

Until 1970, daily fructose intake was between 6 and 12 grams, mainly from fruits. Limited availability and soaring prices for saccharose motivated fructose utilization in gastronomy as an alternative to saccharose. Fructose intake has been rising consistently since 1980. HFCS is currently incorporated in soft drinks, pastry, canned fruits, marmalades and many other processed foods.

Surveys conducted in America ${ }^{38}$ and Europe ${ }^{39}$ have reported that one third of population have increased $25 \%$ its caloric intake in the form of carbohydrates, together with a reduction in nutrients. Caloric intake from simple sugars, glucose and fructose added to beverages and foods raised from $5 \%$ to $13 \%$ of total caloric intake. In soft drinks, fructose represents between $55 \%$ and $58 \%$ of total sugar content ${ }^{40}$. Fructose content is not easily evident for consumers since its presence is often expressed as "HFCS and/or sugar".

Fructose does not require insulin for metabolim, and it is far more reactive than glucose and therefore, it is an important source of AGE generation.

Fat and muscle are the main glucose consumers. In presence of insulin deficit or resistance, glucose cannot be utilized, and other non-insulin-dependent tissues have high availability of intra- and extracellular glucose. High glucose levels generate elevated fructose levels. 
Multiple observations reported between 2013 and 2017 $41-44$ make almost undeniable the pathogenic effects of high fructose intake, especially as HFCS, in generating AGEs. A caveat is therefore relevant: not only saccharose intake must be cut down, but also that of fructose, as much as possible, reducing daily consumption of fruits to 200 to 400 grams.

An in vitro study has reported that artificial non-saccharide sweeteners aspartame and sucralose induce glycation on human and bovine serum albumin, immunoglobulin $\mathrm{G}$, and coagulation factors VIII and IX. This phenomenon could be related to the presence of glucose-like reactive groups that interact with amine groups in lysine. A more recent study has not confirmed these observations and has reported an anti-glycation effect for acesulfame $\operatorname{potassium}^{45,46}$.

\section{Maillard Reaction By-products}

Acrylamide and furan are by-products of Maillard reaction that can potentially increase in the long term the risk of cancer. Acrylamide may also convey potentially noxious effects, such as neurological damage and chromosome alterations. Several international agencies are promoting control measures of involved foods, including french fries, biscuits, pastry, instant coffee, chocolate and cereal-based additives for milk and yogurt (Food Standards Agency: Survey of acrylamide and furan in UK retail products, 2014-2018).

Glycation products are also denominated glycotoxins in view of their pathogenic effects. They participate in free radical generation, activate proinflammatory cytokines, and alter protein and nucleic acid chemical structure and function. Glycotoxins have clear pathogenic roles in diabetes and chronic kidney disease, and possibly in ageing and neurodegenerative diseases. Mitochondrial derangements give foundation to the metabolic theory of cancer, and Maillard reaction by-products potentially increase cancer risk.

\section{Preserving Health}

Human body is furnished with a vast array of antioxidant compounds to protect cells from glycation products. Several foods also provide antioxidant and anti-inflammatory substances, like retinol, ascorbic acid, tocopherol, flavonoids, lycopene, indoles, and luteins, contained in fruits, fresh vegetables, green tea, yerba mate, and wine. 
There have been attempts in clinical nutrition to prevent generation of Amadori products and AGEs. Hydralazine derivatives are more reactive to amine groups than carbonyl ${ }^{47}$. Aminoguanidine has shown to be effective in preventing AGE formation and protein reticulation; these effects have been observed in vitro and in vivo in vascular connective tissue in rats $^{48}$.

AGE inhibitors are being evaluated for clinical use. Pyridoxamine has proved most effective. Several compounds, trace elements and herbs have a purported ability to decrease endogenous AGE damage, among them lipoic acid, carnitine, taurine, benfotiamine, $\alpha$ tocopherol, niacinamide, pyridoxal, riboflavin, selenium, zinc, manganese, carnosine, catechin, quercetin, curcumin, sulforaphane, cinnamon, clove, oregano, garlic, ginger, tea, yerba mate, and chocolate ${ }^{49,50}$.

Research with alcoholic extracts of several spices, especially cinnamon, clove and black pepper, has shown these compounds are effective in reducing protein glycation, related to their content of flavonoids ${ }^{51-53}$. It has been suggested that these products can be added topically to foods before cooking, but confirmatory studies are still lacking.

Ilex paraguariensis, the yerba mate, has a potent antioxidant action, superior to green tea, and an inhibitory effect over AGE generation as potent as that of aminoguanidine; these effects are due to high content in yerba mate of two main phenolic compounds, chlorogenic acid and caffeic $\operatorname{acid}^{54}$. Still other polyphenols (naringin, ellagic acid) and isoflavones (genistein) have been studied regarding their protective effects against glycation ${ }^{55}$.

Since recognition that $\mathrm{HbA} 1 \mathrm{c}$ is the best parameter for diabetes treatment control, several observations in human and in animals have provided knowledge about the role of glycation in the pathogeny of chronic diseases, not related to diabetes. Experts think that preventive measures in dietary habits and lifestyle are warranted.

Cooking methods like boiling, steaming, poaching, stewing or microwaving are preferred, due to lesser temperatures, higher humidity and shorter exposure times, because they generate significantly less glycotoxins. Boiling and steaming reduce logarithmically dAGE generation $^{56}$. Beef acidification with vinegar or lemon juice, one hour before oven or grill cooking, stewing or poaching, reduces glycotoxin generation. Overheating foods before consuming must be avoided.

Reduction in endogenous glycation is achieved mainly by glucose control. Foods with high glycemic index (high saccharose and fructose content) are to be avoided, to reduce glycemic 
load. Daily consumption of 2 or 3 servings of fruit and raw vegetables, as well as spices like turmeric and ginger, provide adequate antioxidant intake.

In theory, antioxidant compounds like resveratrol, present in red wine, are effective in limiting production of oxygen reactive species that accelerate AGE generation ${ }^{57}$. Black chocolate content in flavonoids and polyphenols gives it antioxidant properties, reduces insulin resistance, lowers blood pressure and increases endothelial bioavailability of nitric oxide, reducing cardiovascular risk ${ }^{58}$.

Prebiotics, probiotics, fiber and fermented foods are central in maintaining a healthy intestinal microbial flora. Microbiota biological contribution - microbiome- produces hydrolytic enzymes, required to antioxidant absorption and AGE and ALE sequestering. Lactobacilli may probably eliminate AGEs and ALEs from foods, as well as gluten and carcinogens $^{59}$.

Sport training can also reduce $\mathrm{AGEs}^{60}$. On the contrary, tobacco smokers show elevated levels in lens and blood vessels ${ }^{61}$. In animal models, caloric restriction reduces glycotoxin content in skin collagen ${ }^{62}$.

In conclusion, reduced intake of certain foods (without complete banning them), eventually and not daily consumption, plus changes in lifestyle, can contribute successfully to health preservation (Table 1).

TABLE 1. Attenuating potential pathogenic effects of glycotoxins

\section{Alimentary habits and lifestyle}

- $\quad$ Prefer boiling water, steam or microwave for cooking

- Use lemon juice or vinegar acidification before grill, griddle or oven

- $\quad$ Avoid foods with high glycemic index

- $\quad$ Avoid sugar, glucose and fructose, especially processed foods and soft drinks

- $\quad$ Eat daily 2 or 3 portions of fresh vegetables and fruits

- $\quad$ Use preferently certain spices: turmeric, ginger, cinnamon, clove, black pepper

- $\quad$ Consume tea and yerba mate

- $\quad$ Drink red wine, one glass daily

- $\quad$ Exercise or make a sport 5 days a week 
- $\quad$ Limit alcohol consumption. Quit smoking

- $\quad$ Avoid foods with low nutritional value end high caloric density

\section{References.}

[1] Machields D, Istasse L. La réaction de Maillard: importance et applications an chimie des aliments. Ann Med Vet 2002;148: 347-52

[2] Flores M. Understanding the implications of current health trends on the aroma of wet and dry cured meat products. Meat Sci. 2018; 144: 53-61.

[3] Khaw KT, Wareham N, Luben R, Bingham S, Oakes S, Welch A, Day N. Glycated haemoglobin, diabetes, and mortality in men in Norfolk cohort of european prospective investigation of cancer and nutrition (EPIC-Norfolk). BMJ. 2001; 322:15-8.

[4] Bengmark S. Amplifiers of systemic inflammation: The role advanced glycation and lipoxidation and products in foods. Kuwait Med J. 2008; 40: 3-17.

[5] Uribarri J, del Castillo MD, de la Maza MP, Filip R, Gugliucci A, et al. Dietary advanced glycation end products and their role in health and disease. Adv Nutr. 2015; 6:461-73.

[6] Kalousová M, Zima T, Popov P, Spacek P, Braun M, Soukupová J, Pelinkova K, Kientsch-Engel -R. Advanced glycation end-products in patients with chronic alcohol misuse. Alcohol Alcohol. 2004; 39: 316-20.

[7] Förster A, Kühne Y, Henle T. Studies on absorption and elimination of dietary maillard reaction products. Ann N Y Acad Sci. 2005; 1043: 474-81.

[8] Smedsrød B, Melkko J, Araki N, Sano H, Horiuchi S. Advanced glycation end products are eliminated by scavenger-receptor-mediated endocytosis in hepatic sinusoidal Kupffer and endothelial cells. Biochem J. 1997; 322: 567-73.

[9] De Christopher LR. Perspective: The Paradox in Dietary Advanced Glycation End Products Research-The Source of the Serum and Urinary Advanced Glycation End Products Is the Intestines, Not the Food. Adv Nutr. 2017; 8: 679-83.

[10] Gugliucci A. Formation of Fructose-Mediated Advanced Glycation End Products and Their Roles in Metabolic and Inflammatory Diseases. Adv Nutr. 2017; 8: 54-62. 
[11] Suárez G, Rajaram R, Oronsky AL, Gawinowicz MA. Nonenzymatic glycation of bovine serum albumin by fructose (fructation). Comparison with the Maillard reaction initiated by glucose. J Biol Chem. 1989; 264: 3674-9.

[12] Bains Y, Gugliucci A, Caccavello R. Advanced glycation endproducts form during ovalbumin digestion in the presence of fructose: Inhibition by chlorogenic acid. Fitoterapia. 20171; 120:1-5.

[13] Aragno M, Mastrocola R. Dietary Sugars and Endogenous Formation of Advanced Glycation Endproducts: Emerging Mechanisms of Disease. Nutrients. 2017; 9: 385.

[14] Ramasamy R, Vannucci SJ, Yan SS, et al. Advanced glycation end products and RAGE: a common thread in aging, diabetes, neurodegeneration, and inflammation. Glycobiology. 2005; 15: 16R-28R.

[15] Barzilay JI, Bůžková P, Zieman SJ, et al. Circulating levels of carboxy-methyl-lysine (CML) are associated with hip fracture risk: the Cardiovascular Health Study. J Bone Miner Res. 2014; 29: 1061-6.

[16] Breyer V, Frischmann M, Bidmon C, Schemm A, Schiebel K, Pischetsrieder M. Analysis and biological relevance of advanced glycation end-products of DNA in eukaryotic cells. FEBS J. 2008; 275: 914-25.

[17] González Flecha FL, Castello PR, Gagliardino JJ, Rossi JP. Molecular characterization of the glycated plasma membrane calcium pump. J Membr Biol. 1999; 171: 25-34.

[18] Birlouez-Aragon I, Saavedra G, Tessier FJ, Galinier A, Ait-Ameur L, Lacoste F, Niamba CN, Alt N, Somoza V, Lecerf JM. A diet based on high-heat-treated foods promotes risk factors for diabetes mellitus and cardiovascular diseases. Am J Clin Nutr. 2010 ; 91: 1220-6.

[19] Smit AJ, Gerrits EG. Skin autofluorescence as a measure of advanced glycation endproduct deposition: a novel risk marker in chronic kidney disease. Curr Opin Nephrol Hypertens 2010; 19: 527-33.

[20] Enzinger C, Fazekas F, Matthews PM, Ropele S, Schmidt H, Smith S, Schmidt R. Risk factors for progression of brain atrophy in aging: six-year follow-up of normal subjects. Neurology 2005; 64:1704-11.

[21] Nadeem A, Raj HG, Chhabra SK. Increased oxidative stress and altered levels of antioxidants in chronic obstructive pulmonary disease. Inflammation 2005; 29: 23-32. 
[22] Gorska-Ciebiada M, Saryusz-Wolska M, Borkowska A, Ciebiada M, Loba J. C-Reactive Protein, Advanced Glycation End Products, and Their Receptor in Type 2 Diabetic, Elderly Patients with Mild Cognitive Impairment. Front Aging Neurosci 2015; 29: 209.

[23] Smith MA, Taneda S, Richey PL, Miyata S, Yan SD, Stern D, Sayre LM, Monnier VM, Perry G. Advanced Maillard reaction end products are associated with Alzheimer disease pathology. Proc Natl Acad Sci U S A 1994; 91: 5710-4.

[24] Castellani R, Smith MA, Richey PL, Perry G. Glycoxidation and oxidative stress in Parkinson disease and diffuse Lewy body disease. Brain Res 1996; 737: 195-200.

[25] Dalfó E, Portero-Otín M, Ayala V, Martínez A, Pamplona R, Ferrer I. Evidence of oxidative stress in the neocortex in incidental Lewy body disease. J Neuropathol Exp Neurol 2005; 64: 816-30.

[26] Kaufmann E, Boehm BO, Süssmuth SD, Kientsch-Engel R, Sperfeld A, Ludolph AC, Tumani $\mathrm{H}$. The advanced glycation end-product $\mathrm{N}$ epsilon-(carboxymethyl)lysine level is elevated in cerebrospinal fluid of patients with amyotrophic lateral sclerosis. Neurosci Lett. 2004; 371: 226-9.

[27] Ma L, Nicholson LF. Expression of the receptor for advanced glycation end products in Huntington's disease caudate nucleus. Brain Res. 2004; 1018: 10-7.

[28] Sasaki N, Takeuchi M, Chowei H, Kikuchi S, Hayashi Y, Nakano N, Ikeda H, Yamagishi S, Kitamoto T, Saito T, Makita Z. Advanced glycation end products (AGE) and their receptor (RAGE) in the brain of patients with Creutzfeldt-Jakob disease with prion plaques. Neurosci Lett. 2002; 326: 117-20.

[29] Diamanti-Kandarakis E, Piperi C, Kalofoutis A, Creatsas G. Increased levels of serum advanced glycation end-products in women with polycystic ovary syndrome. Clin Endocrinol (Oxf). 2005; 62: 37-43.

[30] Voyer LE, Bruno O, Ibarra L, y col. Nefropatía diabetic en la infancia. . Rev Hosp Gral Niños Pedro Elizalde. 1997; 7: 23-30.

[31] Rosenbloom AL, Silverstein JH, Lezotte DC, Richardson K, McCallum M. Limited joint mobility in childhood diabetes mellitus indicates increased risk for microvascular disease. N Engl J Med. 1981; 305: 191-4.

[32] Voyer LE. Síndromes malformativos. Secuencia de retracción caudal. En: Voyer. Ruvinski, Cambiano. Pediatría. 3erd ed. Buenos Aires. Editorial Journal. 2011. p. 1102. 
[33] Uribarri J, Peppa M, Cai W, Goldberg T, Lu M, He C, Vlassara H. Restriction of dietary glycotoxins reduces excessive advanced glycation end products in renal failure patients. J Am Soc Nephrol. 2003; 14: 728-31.

[34] Gerrits EG, Lutgers HL, Smeets GH, Groenier KH, Smit AJ, Gans RO, Bilo HJ. Skin autofluorescence: a pronounced marker of mortality in hemodialysis patients. Nephron Extra. 2012; 2: 184-91.

[35] Gogvadze V, Orrenius S, Zhivotovsky B. Mitochondria in cancer cells: what is so special about them? Trends Cell Biol. 2008; 18: 165-73.

[36] Gonzalez MJ, Miranda Massari JR, Duconge J, Riordan NH, Ichim T, Quintero-Del-Rio AI, Ortiz N. The bio-energetic theory of carcinogenesis. Med Hypotheses. 2012 ; 79: 433-9.

[37] Semba RD, Gebauer SK, Baer DJ, Sun K, Turner R, Silber HA, Talegawkar S, Ferrucci L, Novotny JA. Dietary intake of advanced glycation end products did not affect endothelial function and inflammation in healthy adults in a randomized controlled trial. J Nutr. 2014; 144: 1037-42.

[38] Marriott BP, Olsho L, Hadden L, Connor P. Intake of added sugars and selected nutrients in the United States, National Health and Nutrition Examination Survey (NHANES) 2003-2006. Crit Rev Food Sci Nutr. 2010; 50: 228-58.

[39] Azaïs-Braesco V, Sluik D, Maillot M, Kok F, Moreno LA. A review of total \& added sugar intakes and dietary sources in Europe. Nutr J. 2017; 16: 6.

[40] White JS, Hobbs LJ, Fernandez S. Fructose content and composition of commercial HFCS-sweetened carbonated beverages. Int J Obes (Lond). 2015; 39: 176-82

[41] Poulsen MW, Hedegaard RV, Andersen JM, de Courten B, Bügel S, Nielsen J, Skibsted LH, Dragsted LO. Advanced glycation endproducts in food and their effects on health. Food Chem Toxicol. 2013; 60: 10-37.

[42] DeChristopher LR, Uribarri J, Tucker KL. Intake of high-fructose corn syrup sweetened soft drinks, fruit drinks and apple juice is associated with prevalent arthritis in US adults, aged 20-30 years. Nutr Diabetes. 2016; 6: e199.

[43] DeChristopher LR, Uribarri J, Tucker KL. Intakes of apple juice, fruit drinks and soda are associated with prevalent asthma in US children aged 2-9 years. Public Health Nutr. $2016 ; 19: 123-30$. 
[44] Aragno M, Mastrocola R. Dietary Sugars and Endogenous Formation of Advanced Glycation Endproducts: Emerging Mechanisms of Disease. Nutrients. 2017; 9: 385.

[45] Ali A, Devrukhkas J. In vitro study on glycation of plasma protein with artificial sweeteners. Biol Szeged 2016; 65: 7.

[46] Ali A, More TA, Hoonjan AK, Sivakami S. Antiglycating potential of acesulfame potassium: an artificial sweetener. Appl Physiol Nutr Metab. 2017; 42: 1054-63.

[47] Khalifah RG, Baynes JW, Hudson BG. Amadorins: novel post-Amadori inhibitors of advanced glycation reactions. Biochem Biophys Res Commun. 1999; 257: 251-8

[48] Zimmerman GA, Meistrell M 3rd, Bloom O, Cockroft KM, Bianchi M, Risucci D, Broome J, Farmer P, Cerami A, Vlassara H, et al. Neurotoxicity of advanced glycation endproducts during focal stroke and neuroprotective effects of aminoguanidine. Proc Natl Acad Sci U S A. 1995; 92: 3744-8.

[49] Hagen TM, Liu J, Lykkesfeldt J, Wehr CM, Ingersoll RT, Vinarsky V, Bartholomew JC, Ames BN. Feeding acetyl-L-carnitine and lipoic acid to old rats significantly improves metabolic function while decreasing oxidative stress. Proc Natl Acad Sci U S A. 2002 ; 99: $1870-5$.

[50] Nandhini AT, Thirunavukkarasu V, Anuradha CV. Taurine prevents collagen abnormalities in high fructose-fed rats. Indian J Med Res. 2005; 122: 171-7.

[51] Kim CS, Park S, Kim J. The role of glycation in the pathogenesis of aging and its prevention through herbal products and physical exercise. J Exerc Nutrition Biochem. 2017; 21: 55-61.

[52] Yamagishi SI, Matsui T, Ishibashi Y, Isami F, Abe Y, Sakaguchi T, Higashimoto Y. Phytochemicals Against Advanced Glycation End Products (AGEs) and the Receptor System. Curr Pharm Des. 2017; 23: 1135-41.

[53] Jessica Elizabeth T, Gassara F, Kouassi AP, Brar SK, Belkacemi K. Spice use in food: Properties and benefits. Crit Rev Food Sci Nutr. 2017; 57: 1078-88.

[54] Bains Y, Gugliucci A. Ilex paraguariensis and its main component chlorogenic acid inhibit fructose formation of advanced glycation endproducts with amino acids at conditions compatible with those in the digestive system. Fitoterapia. 2017; 117: 6-10.

[55] Kong Y, Li X, Zheng T, Lv L. Glycation of $\beta$-lactoglobulin and antiglycation by genistein in different reactive carbonyl model systems. Food Chem. 2015; 183: 36-42. 
[56] Uribarri J, Woodruff S, Goodman S, Cai W, Chen X, Pyzik R, Yong A, Striker GE, Vlassara H. Advanced glycation end products in foods and a practical guide to their reduction in the diet. J Am Diet Assoc. 2010; 110: 911-16.e12.

[57] Liu Y, He XQ, Huang X, Ding L, Xu L, Shen YT, Zhang F, Zhu MB, Xu BH, Qi ZQ, Wang HL. Resveratrol protects mouse oocytes from methylglyoxal-induced oxidative damage. PLoS One. 2013; 8: e77960.

[58] Ried K, Sullivan T, Fakler P, Frank OR, Stocks NP. Does chocolate reduce blood pressure? A meta-analysis. BMC Med. 2010; 8: 39.

[59] di Cagno R, de Angelis M, Alfonsi G, de Vincenzi M, Silano M, Vincentini O, Gobbetti M. Pasta made from durum wheat semolina fermented with selected lactobacilli as a tool for a potential decrease of the gluten intolerance. J Agric Food Chem. 2005; 53: 4393 402.

[60] Couppé C, Svensson RB, Grosset JF, Kovanen V, Nielsen RH, Olsen MR, Larsen JO, Praet SF, Skovgaard D, Hansen M, Aagaard P, Kjaer M, Magnusson SP. Life-long endurance running is associated with reduced glycation and mechanical stress in connective tissue. Age (Dordr). 2014; 36: 9665.

[61] Nicholl ID, Stitt AW, Moore JE, Ritchie AJ, Archer DB, Bucala R. Increased levels of advanced glycation endproducts in the lenses and blood vessels of cigarette smokers. Mol Med. 1998; 4: 594-601.

[62] Cefalu WT, Bell-Farrow AD, Wang ZQ, Sonntag WE, Fu MX, Baynes JW, Thorpe SR. Caloric restriction decreases age-dependent accumulation of the glycoxidation products, $\mathrm{N}$ epsilon-(carboxymethyl) lysine and pentosidine, in rat skin collagen. J Gerontol A Biol Sci Med Sci. 1995; 50: B337-41. 